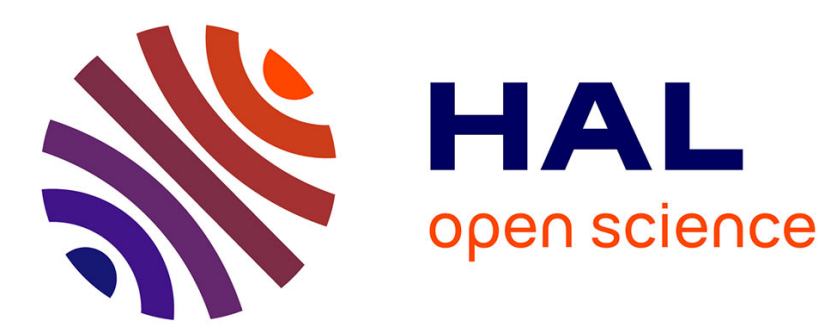

\title{
Development of an artificial vision progressive local method for auto tracking of vine rows
}

\author{
B. Benet, R. Lenain, V. Rousseau
}

\section{To cite this version:}

B. Benet, R. Lenain, V. Rousseau. Development of an artificial vision progressive local method for auto tracking of vine rows. 10th European Conference on Precision Agriculture (ECPA2015), Jul 2015, Beit Dagan, Israel. hal-01297395

\section{HAL Id: hal-01297395 \\ https://hal.science/hal-01297395}

Submitted on 6 Apr 2016

HAL is a multi-disciplinary open access archive for the deposit and dissemination of scientific research documents, whether they are published or not. The documents may come from teaching and research institutions in France or abroad, or from public or private research centers.
L'archive ouverte pluridisciplinaire HAL, est destinée au dépôt et à la diffusion de documents scientifiques de niveau recherche, publiés ou non, émanant des établissements d'enseignement et de recherche français ou étrangers, des laboratoires publics ou privés. 


\title{
Development of an artificial vision progressive local method for auto tracking of vine rows
}

Benet B., Lenain R., Rousseau V.

IRSTEA, UR TSCF, 9 avenue Blaise Pascal, 63178 Aubière, France

bernard.benet@irstea.fr

\begin{abstract}
For automated maintenance operations for vines, a vision system, with one embedded camera on a mobile robot, was developed in order to detect and locate, in real time, vine trunks and to achieve automatic vehicle guidance close to the crop rows, to perform the task. The image processing algorithm developed consisted of a series of operations. Some of them include variable parameters depending on the research area in the images. The applied operations are classification techniques to separate vine trunks from other elements (ground, grass or leave), a mathematical morphology method, a labeling operation and a computation of geometric parameters on identified objects. To identify vine trunks, geometric models that characterize this element were used. A linear regression was finally applied to determine the vine trunks line. The success rate obtained with this vision method, working in RGB or HIS space, to detect the vines, was $90 \%$, on a bank of 300 images acquired at different vegetation stages, with some perturbations like variable lighting conditions and shadow presence.
\end{abstract}

Keywords: Image processing, vines, culture row tracking

\section{Introduction}

Autonomous robotic system development, used for maintenance operations such as weeding, hold promise toward the automation of one of agriculture's few remaining non-mechanized tasks, such as hand weed control (Slaughter, D.C., 2007). Robotic technology, with the use of different sensors such as GPS, cameras or lasers to detect and locate weeds could reduce dependency on herbicides, improving sustainability and reducing environmental impact. Various automatic systems have demonstrated the potential of this technology in the field, for various crops. Automated guidance of the machinery not only reduces operator fatigue but also increases both the productivity and safety of the operation. An essential aspect of automatic guidance is the ability to identify the pathway between the crop rows. Research activities concerning automatic guidance of agricultural vehicles have led to various solutions (Keicher \& Seufer, 2000). Sensors, including mechanical ones, global navigation satellite systems, machine vision, laser triangulation, ultrasonic, can generate position, attitude and direction-ofmovement information as input to control algorithms. A review of research in agricultural vehicle guidance technologies was presented in Ming et al (2009), with the analysis of guidance system characteristics. GPS and machine vision fused together, and also with others technologies, are the trend for agricultural vehicle guidance systems. In a vision-based automatic guidance system for row-crop applications, finding guidance information such as known crop row spacing is a solution for achieving accurate control of the vehicle and improvement of measurement accuracy (Han et al, 2004). Current production navigation systems for agricultural vehicles rely on GPS as the primary 
sensor for steering control. However, for different crops, like for example citrus groves, the tree canopy frequently blocks the satellite signals to the GPS receiver. In these conditions, an alternative method using a vision system and a laser radar has been developed to navigate a tractor (Subramanian et al, 2006). As most crops are cultivated in rows, an important step towards this long-term goal is the development of a rowrecognition system, which allows a robot to accurately follow a row of plants. As examples of guidance devices using artificial vision, Bakker et al (2007) and Astrand \& Baerveldt (2004), used methods for recognition of plant rows based on the Hough transform, tested them on sugar beets and rape. Bellingsley \& Schoenfisch (1995) proposed a guidance device to follow rows of cotton crops. Vision guidance systems using a stereovision device have also been developed (Kise et al, 2005) to get information on a 3D environment. Supervised guidance systems have also been developed for positioning mechanical or thermal tools correctly near crops (Peruzzi et al, 2012). For vision guidance operations, the acquired images are sensitive to vehicle vibrations. Studies have also been undertaken to improve detection of crop rows, by vision, taking into account the perturbations caused by some unwanted movements of tractor with an embedded camera (Ruiz-Ruiz et al, 2012) and (Sainz-Costa et al, 2012). This paper proposes a method to detect and locate vine trunks, by vision, after discriminating the elements vine trunk, ground, leaf and grass, on images, to obtain finally the vine row, in real time. From the vision information, a lateral deviation computation between the vehicle and the row is done, and maintenance tasks near trunk vines can be carried out. The work was realized in a relative mode using a camera, instead of working in an absolute mode with a GPS. The aim was to develop a system, without learning path for guidance, which can adapt to various grounds and vegetation stages and which takes into account variable sizes of vine trunks in the images and lighting variations.

\section{Materials and methods}

The vehicle used for carrying the vision sensor which performed data acquisition and image processing operations in vines is a mobile robot with an embedded color camera (resolution $1280 \times 720$ ) (Figure 1). The images were acquired on vines corresponding to two vegetation stages (with (a) and without (b) leaves).

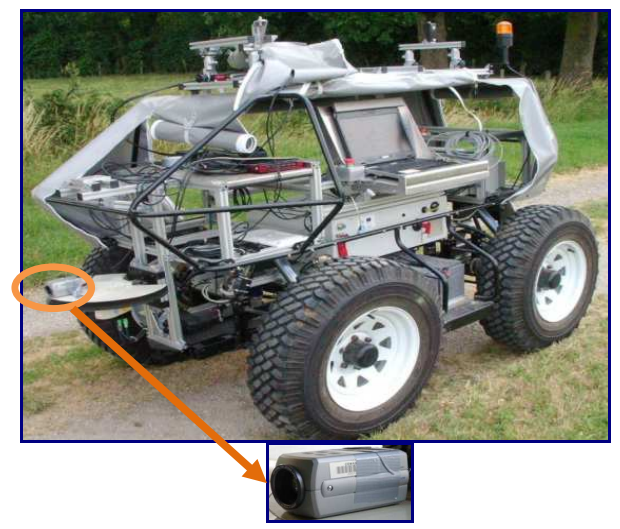

a)

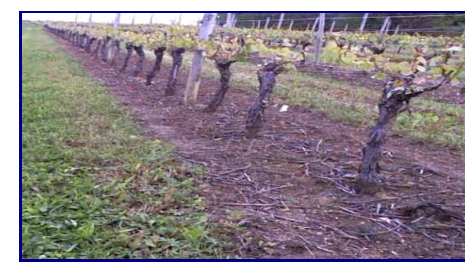

b)

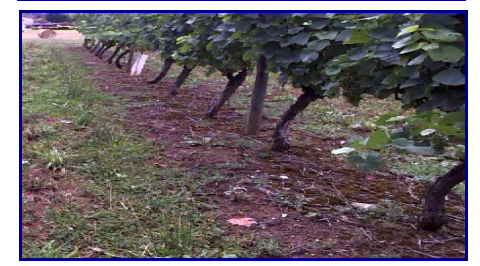

Figure 1. Mobile robot with a color camera and vines. 
The image processing algorithm developed to detect and locate vine trunks, consisted of a series of operations. Some of them have variable parameters according to the research area in the images. The goal was to locate vine trunks, especially their lowest point on the images. The image spaces tested were RGB (Red Green Blue) and HIS (Hue Intensity Saturation). Figure 2 shows images corresponding to HIS space, with the computation formula between RGB and HIS spaces.

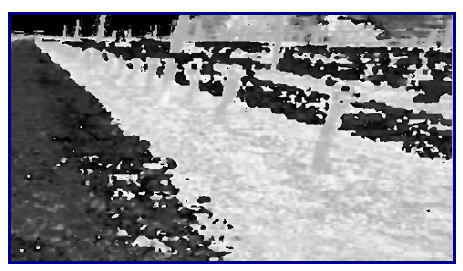

$\mathrm{H}=\operatorname{acos}(\mathrm{F} / \mathrm{V})$

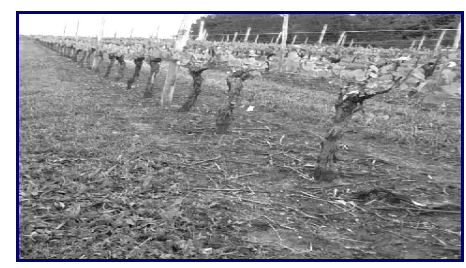

$\mathrm{I}=(\mathrm{R}+\mathrm{G}+\mathrm{B}) / 3$

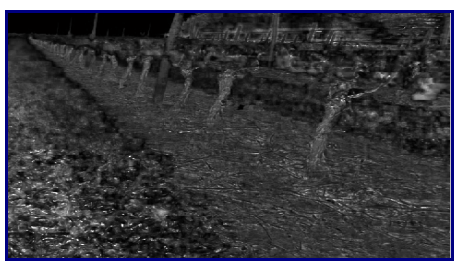

$\mathrm{S}=1-(\min (\mathrm{R}, \mathrm{G}, \mathrm{B})) / \mathrm{I}$

$\mathrm{F}=0,5 \cdot(\mathrm{R}-\mathrm{G})+(\mathrm{R}-\mathrm{B})$

$\mathrm{V}=\left((\mathrm{R}-\mathrm{G})^{2}+(\mathrm{R}-\mathrm{B}) \cdot(\mathrm{G}-\mathrm{B})\right)^{0,5}$

Figure 2. Vine images in HIS space.

Texture parameters such as contrast and energy were also tested to discriminate the vine trunks from the other three classes, with a threshold operation. For each pixel, the texture parameters were computed in a window (3-3) around the pixel.

Contrast: $\mathrm{C}=\sum_{i_{l} \mid}|i-j|^{2} p\left(i_{*} j\right) \quad$ Energy: $\mathrm{E}=\sum_{t_{l} j} p\left(i_{s} j\right)^{2}$

$\mathrm{p}(\mathrm{i}, \mathrm{j})$ is the pixel value in I space at position $(i, j)$ on the image

Firstly, in the vision algorithm, an object classification method, like SVM (Support Vector Machine) or ANN (Artificial Neural Network), was applied to discriminate the vine trunk class from the three classes, grass, ground and leaf in the vine environment. For the SVM method (Hyeran \& Seong-Whan, 2002), the principle is to separate two classes (Figure 3).

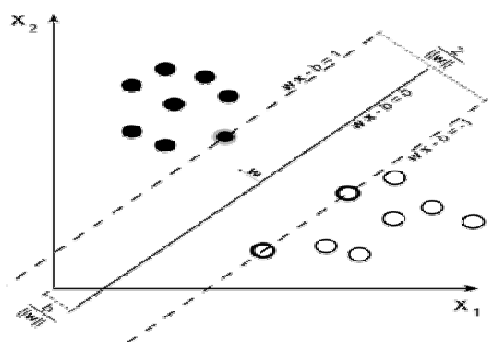

The distance between two hyperplanes is

$$
\frac{2}{\|\mathbf{w}\|}
$$

The objective is to minimize $\mathrm{w}$

The following constraint, is added for each pixel $i$ :

$\mathrm{y}_{\mathrm{i}}=+1, \quad \mathrm{w}_{\mathrm{i}}-\mathrm{b} \geq 1 \quad$ if $\mathrm{x}_{\mathrm{i}} \in$ first class

$\mathrm{y}_{\mathrm{i}}=-1, \quad$ w $\mathrm{x}_{\mathrm{i}}-\mathrm{b} \leq-1 \quad$ if $\mathrm{x}_{\mathrm{i}} \in$ second class

This can be rewritten as: $\mathrm{y}_{\mathrm{i}}\left(\mathrm{w}^{\prime} \mathrm{x}_{\mathrm{i}}-\mathrm{b}\right) \geq 1$ for $1 \leq \mathrm{i} \leq \mathrm{n}$

Figure 3. SVM method to discriminate two objects in an image.

The principle of the neural network method (Krenker \& Bester, 2011), with the different equations, is presented in Figure 4. First, a learning operation was carried out considering color samples of the four objects, minimizing an error calculation and computing the weights of the different layers, to create the network. The input data were RGB or HIS components for each pixel; the output values were one index value $(1,2,3$ and 4$)$ to identify each of the four clases (vine trunk, grass, ground, leaf). Different hidden layer numbers were defined, to obtain the best network as possible. Then, the test operation consisted of determining the class of all pixels in the vine images. 

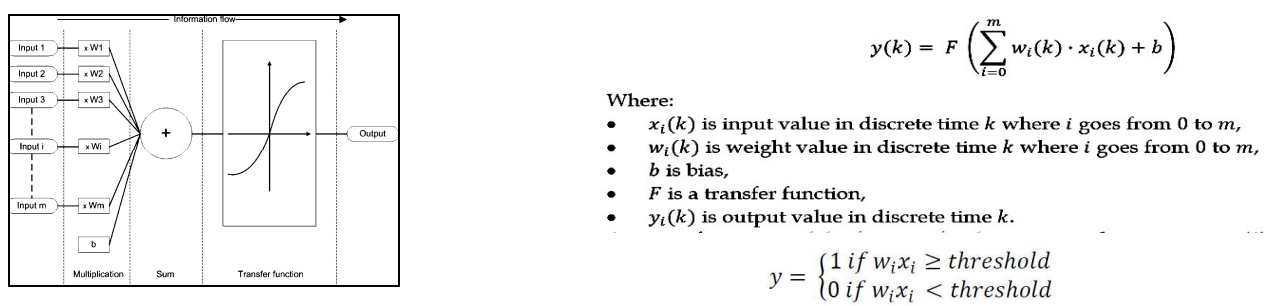

Figure 4. Neural network building principle to separate some classes in images.

Secondly, a mathematical morphology operation was applied to remove noise, then a labeling operation, to obtain separated objects (vine trunks or noise), and a geometric computation on identified objects for identifying vine trunks, using models that characterize them were undertaken. A linear regression was finally applied to determine the vine lines, taking into account the lowest point of the trunks in the images. The artificial vision method developed consisted of searching vine trunks one after the other, in successive images. After the detection of one trunk, a new research area was created to look for a new one. To take into account the variable sizes of trunks in the image, different parameters of the image processing operations (morphology function, geometric parameters) were defined for each research area. Figure 5 presents the image processing algorithm developed to detect vine trunks in images and achieve the autotracking of vine rows. Xmax and Ymax are respectively the image width (1280 pixels) and height (720 pixels).

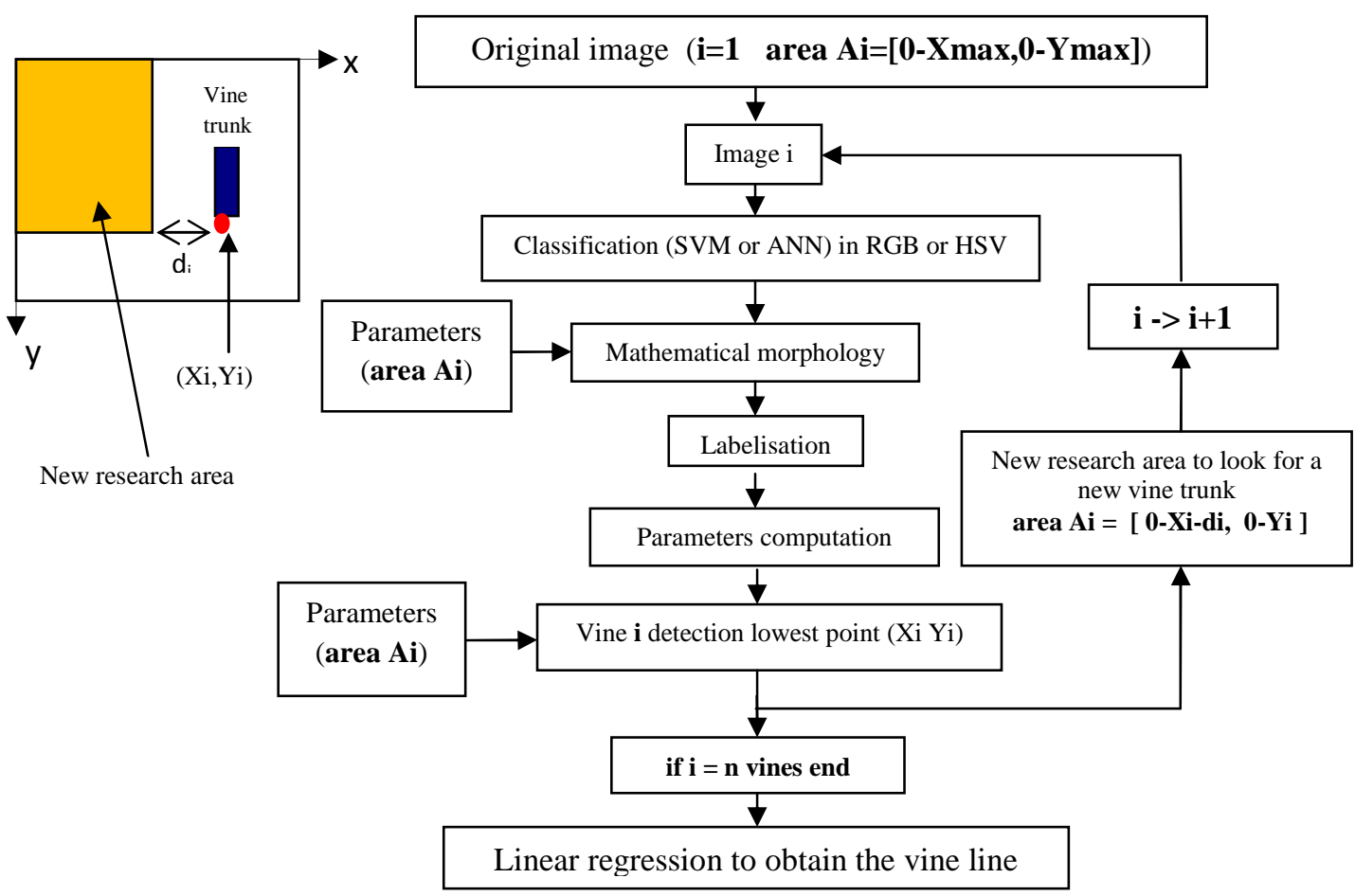

Figure 5. Image processing algorithm to detect vine trunks and obtain vine row.

For each captured image, a brightness test was performed to see if the light intensity was very different from reference intensity. In the beginning, this operation with SVM 
or ANN method was performed with a reference image corresponding to an average intensity named $\mathrm{I}_{\text {ref. }}$. If one given image had an average intensity $\mathrm{I}_{\text {mean }}$ very different from $I_{\text {ref }}\left(\left|I_{\text {mean }}-I_{\text {ref }}\right|>\right.$ Threshold), then the point bases HIS (Base_H, Base_I, Base_S) were modified for the four classes used for classification to obtain new bases (NewBase_H, NewBase_I, NewBase_S) (2). An automatic classification was achieved with these data, and the HIS point values were also modified to obtain a new image. Then all the algorithm operations (class discrimination, morphology,...) were applied to this image.

$$
\begin{array}{lll}
\text { coef_I }=\mathrm{I}_{\text {mean }} / \mathrm{I}_{\text {ref }} & \text { NewBase_I }=\text { Base_I x coef_I } & \text { Inew }=\mathrm{I} \text { x coef_I } \\
\text { coef_H }=\mathrm{H}_{\text {mean }} / \mathrm{H}_{\text {ref }} & \text { NewBase_H }=\text { Base_H x coef_H } & \text { Hnew }=\mathrm{H} \text { x coef_H } \\
\text { coef_S }=\mathrm{S}_{\text {mean }} / \mathrm{S}_{\text {ref }} & \text { NewBase_S }=\text { Base_S x coef_S } & \text { Snew }=\mathrm{S} \text { x coef_S }
\end{array}
$$

\section{Results}

\section{$\underline{\text { Classification method for vine environment }}$}

For classification, SVM and ANN methods, in RGB and HIS color spaces, gave correct results to separate the vines from others elements (grass, ground, leaf) considering both vegetation stages (Figure 6). Discrimination was not reliable in the texture parameters space tested. In the application, it was noticed that the SVM method was faster than the ANN method. However, there is always a classification result, with the ANN method, even if there is not an important difference between pixel bases, whereas the SVM method can sometimes diverge, if the difference between pixel classes is not very significant.
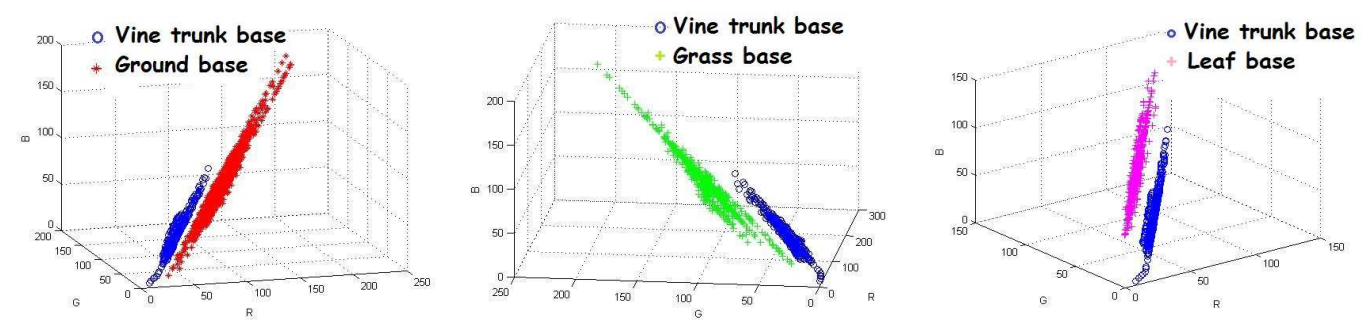

Figure 6. Pixel bases in RGB space used to discriminate the four classes.

Detection of vines row taking into account the research area of each vine individually

A result example of the different image processing operations is presented in Figure 7 (a - d), for one global image. The geometric data of detected objects (vine trunks and noise (other elements)) are shown in Table 1. In the developed local detection method, the classification operation was undertaken once but the morphology, labelisation and identification operations were carried out at each step, with different parameter sets depending on the research area (Table 2). These geometric parameters are the following: Opening M (Mathematical Morphology), Surface A (pixel number for each object), Elongation $\mathbf{E}$ (ratio between major axis length and minor axis length) and Orientation $\mathbf{O}$ (orientation angle of an object). After detection of each vine trunk, a new research area was created, taking into account the lowest point of this detected trunk and a horizontal deviation $\mathrm{d}_{\mathrm{i}}$, to look for a new one. 


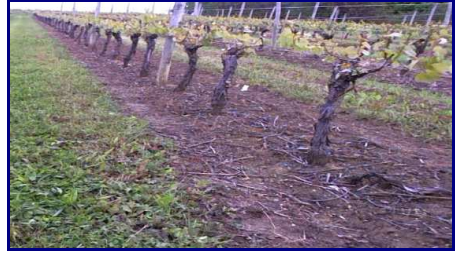

a) Original vine image

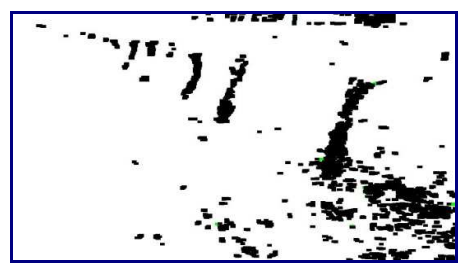

c) Mathematical morphology

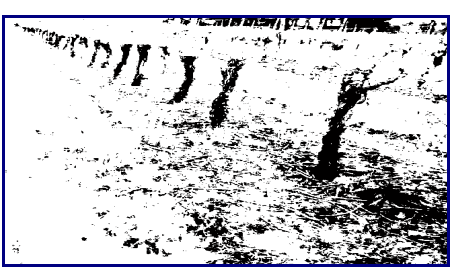

b) Classification

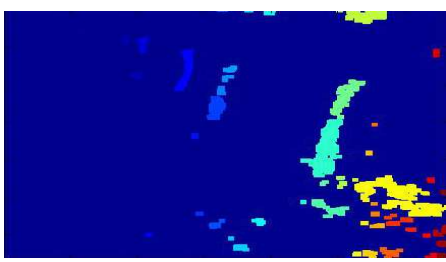

d) Labelisation

Figure 7. Image processing operations to identify vine trunks.

Table 1. Geometric data of detected objects (vine trunks and other elements).

\begin{tabular}{|c|c|c|c|c|c|c|c|c|c|c|c|c|c|}
\hline Detected object & 1 & 2 & 3 & 4 & 5 & 6 & 7 & 8 & 9 & 10 & 11 & 12 & 13 \\
\hline Surface & 223 & 195 & 366 & 195 & 672 & 557 & 219 & 207 & 173 & 1329 & 246 & 1344 & 1244 \\
\hline Orientation & -7 & 33 & 89 & 62 & 86 & 87 & -16 & -88 & -83 & 0 & 44 & 82 & 79 \\
\hline Elongation & 1.9 & 1.2 & 2.5 & 1.1 & 2.7 & 2.8 & 1.6 & 1.2 & 1.3 & 3.3 & 1.3 & 3.3 & 3.1 \\
\hline
\end{tabular}

Table 2. Trunk identification parameters for each research area.

\begin{tabular}{|c|c|c|c|c|c|}
\hline Research area (horizontal axis) & $\mathbf{M}$ & $\mathbf{E}$ & $\mathbf{0}$ & $\mathbf{A}$ & $\mathbf{d}_{\mathbf{i}}$ \\
\hline$[0-$ Xmax $]$ & 10 & 3 & $-50^{\circ}+50^{\circ}$ & 1000 & 130 \\
{$[0-560]$} & 10 & 2 & $-50^{\circ}+50^{\circ}$ & 500 & 60 \\
{$[0-500]$} & 5 & 1,5 & $-50^{\circ}+50^{\circ}$ & 300 & 40 \\
{$[0-430]$} & 2 & 1 & $-50^{\circ} 50^{\circ}$ & 200 & 30 \\
{$[0-330]$} & 1 & 1 & $-40^{\circ} 40^{\circ}$ & 150 & 20 \\
\hline
\end{tabular}
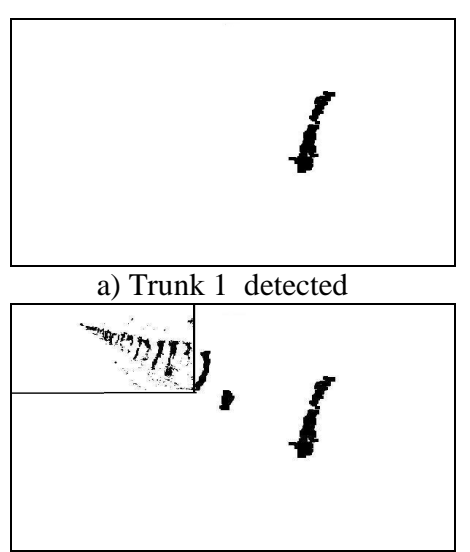

d) Trunk 3 detected

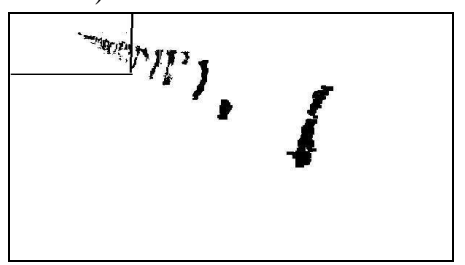

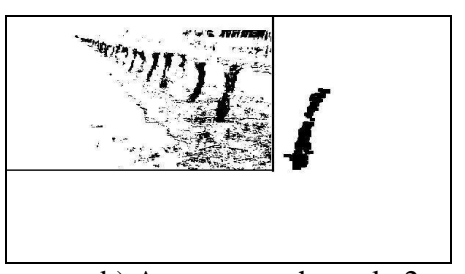

b) Area to search trunk 2

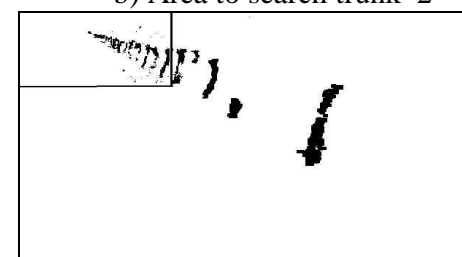

e) Trunk 4 detected

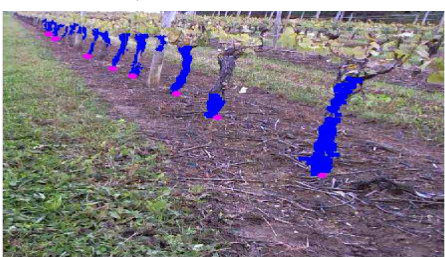

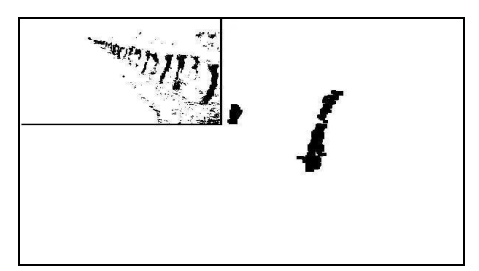

c) Trunk 2 detected

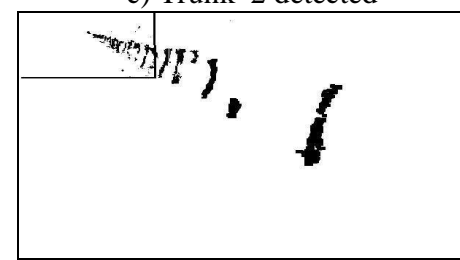

f) Trunk 5 detected

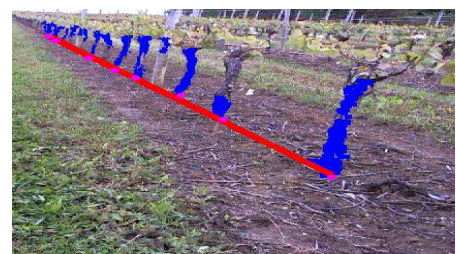

g) Trunk 6 detected

h) Localization of lowest point of all vine trunks

i) Vine line detection

Figure 8 . Vine trunk detection and determination of the vine line. 
$\underline{\text { Vine trunks detection taking into account highlighting variations }}$

Figure 9 shows a result obtained, taking into account high-lighting variation between the reference image (a) used for classification and one image (c) ( $\left|I_{\text {mean }}-I_{\text {ref }}\right|>0.2$ (Threshold value)). Classification operation results for both images are presented respectively in images (b) and (d). The vine trunk line detection result for image (d) is shown on image (e).

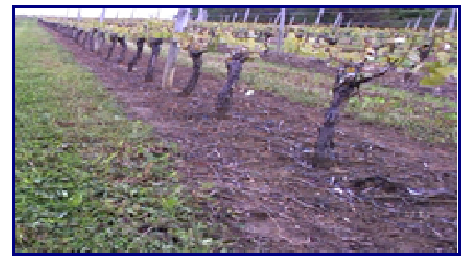

a) Vine image with

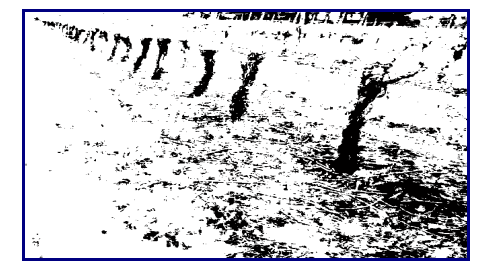

b) Classification result for image (a)

$\mathrm{I}_{\mathrm{ref}}=0,53 \quad \mathrm{~S}_{\mathrm{ref}}=0,22 \quad \mathrm{H}_{\mathrm{ref}}=0,44$

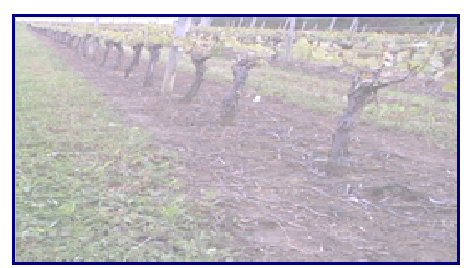

c) Vine image with

$I_{\text {mean }}=0,76 \quad S_{\text {mean }}=0,07 \quad H_{\text {mean }}=0,44$

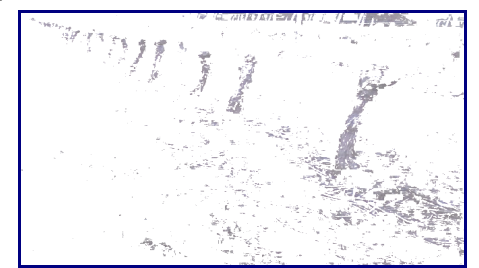

d) Classification result for image (c)

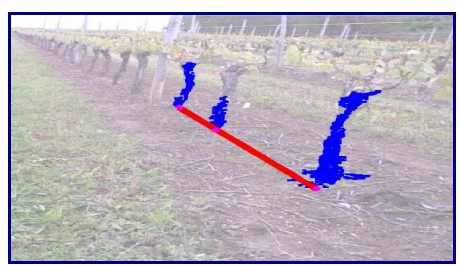

e) Vine line detection

Figure 9. Vine line detection result taking into account the high lighting variation.

This study was conducted in order to work in variable lighting conditions in the agricultural environment, for detecting vines automatically, with the application of an automatic classification for the four pixel classes, if necessary. Working with fixed permanent bases, some vine trunks could not be detected, either in RGB or HIS space, for high-lighting variations. To remedy this light problem, another (and faster) solution would be to perform several manual classifications corresponding to different light levels, and then choose, in real time, the best one, according to the light level of the environment to detect the vines.

To improve the accuracy on vine line detection results, further research will consist of using a lidar sensor, complementary to the camera, to locate, in a fusion mode, vine trunks. It will be also interesting to modify the acquisition conditions (zooming, centering trunks on images), using for example a pan-tilt-zoom camera, to detect some small vine trunks and increase vine trunk number in images. This vine line detection application will be tested on others cultures, to test its robustness.

\section{Conclusion}

The vision method developed consisted of searching vine trunks one after the other, automatically modifying at each step, some parameters in the algorithm, in order to detect the most as possible vine trunks in images. If there was a significant lighting variation between a reference image and one captured image, then, before applying the vision algorithm, the database points for the four classes (vine trunk, grass, leaf and ground) were modified to achieve an automatic classification phase and the pixels in the 
image were also modified, in HIS space. The success rate was $90 \%$, working on a bank of 300 images. The errors obtained in the detection are due to two main reasons: the shadow problems near the vines and large color variation between different vine trunks but also within the same element. From the vine row information, referenced-vision guidance operations are applied to control a vehicle which follows the vine lines and carries out maintenance operations. For classification, SVM and ANN methods, in RGB and HIS color spaces, separated with accuracy the vine trunks from others elements (grass, ground and leaf).

\section{References}

Astrand, B. and Baerveldt, A.J., 2005. Based row-following system for agricultural field Machinery. Mechatronics 15 (2) 251-269.

Bakker, T., Wouters, H., Asselt, K., Bontsema, J., Tang, L., Muller, J., Straten, G., 2007. A vision based row detection system for sugar beet. Computers and Electronics in Agriculture 60 (1) 87-95.

Billingssley, J. and Schoenfisch, M., 1995. Vision-Guidance of Agricultural Vehicles. Autonomous Robots 2, 65-76.

Han, S., Zhang, Q., Ni, B., Reid, J.F., 2003. A guidance directrix approach to visionbased vehicle guidance systems. Computers and Electronics in Agriculture 43 (3) 179-195.

Hyeran, B., Seong-Whan, L., 2002. Applications of Support Vector Machines for Pattern Recognition:A Survey. Lecture Notes in Computer Science 2388 213-236.

Keicher, R. and Seufert, H., 2000. Automatic guidance for agricultural vehicles in Europe. Computers and Electronics in Agriculture 25 (1-2) 169-194.

Kise, M., Zhang, Q., Rovira Mas, F., 2004. A Stereovision-based Crop Row Detection Method for Tractor-automated- Biosystems Engineering 90 (4) 357-367.

Krenker, A. and Bester, J., 2011. Introduction to the Artificial Neural Networks Faculty of Electrical Engineering, University of Ljubljana, Slovenia.

Li, M., Imou, K.,Wakabayashi, K., Yokoyama, S., 2009. Review of research on agricultural vehicle autonomous guidance. IJABE 2, $\mathrm{N}^{\circ} 3$.

Peruzzi, A., Raffaelli, M., Frasconi, C., Martelloni, L., Fontanelli, M., Sarri, D., Lisci, R., Rimediotti, M., Vieri, M., 2012. An autonomous ground mobile unit for the precision physical weed Control - Presented at CIGR-AgEng 2012 C-1842.

Ruiz-Ruiz, G., Navas-Gracia, L., Gómez-Gil, J., 2012. Camera kinetic model applied to crop row tracking and weed detection - Presented at CIGR-AgEng 2012 P1136.

Sainz-Costa, N., Burgos-Artizzu, X. P., Herrera, P. J., Ribeiro, A., 2012. An empirical study on the viability of the application of SIFT algorithm to video stabilization in crop fields - Presented at CIGR-AgEng Valencia 2012 C-2073.

Slaughter, D.C., Giles, D.K., Downey, D., 2008. Autonomous robotic weed control systems: A review. Computers and Electronics in Agriculture 61 (1) 63-78.

Subramanian, V., Burks, T.S., Arroyo, A.A., 2006. Development of machine vision and laser radar based autonomous vehicle guidance systems for citrus grove navigation. Computers and Electronics in Agriculture 53 (2) 130-143. 